\title{
PROPAGATION OF STRESS WAVES IN ALPINE SNOW
}

\author{
By R. L. BROwN* \\ (U.S. Army Cold Regions Research and Engineering Laboratory, Hanover, New \\ Hampshire 03755, U.S.A.)
}

\begin{abstract}
The propagation of pressure waves in low-density snow is investigated analytically to determine the variation of wave pressure and wave speed with density and frequency. The results show that, for pressure waves that produce finite volumetric deformations, both pressure jump across the wave and wave-speed increase with initial density and final density. The pressure jump was also found to increase with the wave frequency if other parameters were held constant, although the dependence on frequency is not as strong as the dependence on the initial and final densities. The relationship between pressure jump and frequency implies that high-frequency waves would tend to dissipate more quickly than lower-frequency waves, although like pressure, the attenuation rate would not be strongly frequency dependent.

RÉsumé. Propagation des ondes de pression dans la neige alpine. On a inventorié analytiquement la propagation des ondes de pression dans une neige de faible densité afin de déterminer la variation de l'onde de pression et de l'onde de vitesse selon la densité et la fréquence. Les résultats montrent que, pour les ondes de pression qui produisent des déformations volumétriques finies, aussi bien le saut de pression au passage de l'onde que la vitesse de l'onde elle-même augmentent avec la densité initiale et la densité finale. On a aussi trouvé que le saut de pression augmentait avec la fréquence de l'onde si les autres paramètres sont maintenus constants bien que la dépendance de la fréquence ne soit pas aussi stricte que la dépendance des densités initiales et finales. La relation entre le saut de pression et la fréquence implique que les ondes de haute fréquence devraient avoir tendance à se dissiper plus vite que les ondes à fréquence plus basse, bien que, comme la pression, la vitesse d'atténuation ne serait pas aussi strictement dépendante de la fréquence.

Zusammenfassung. Fortpflanzung von Druckwellen in alpinem Schnee. Zur Bestimmung der Änderung des Wellendruckes und der Wellengeschwindigkeit in Abhängigkeit von der Dichte und Frequenz wird die Fortpflanzung von Druckwellen in lockerem Schnee analytisch untersucht. Es zeigt sich, dass bei Druckwellen, die finite Deformationen des Volumens hervorrufen, sowohl der Druckanstieg quer zur Welle wie die Wellengeschwindigkeit mit anfänglicher und endgültiger Dichte zunehmen. Eine Zunahme des Druckanstiegs ergab sich auch mit der Wellenfrequenz bei Konstanthaltung anderer Parameter, obwohl die Frequenzabhängigkeit nicht so stark ist als die von der Anfangs- und Ausgangsdichte. Die Beziehung zwischen Druckanstieg und Frequenz lässt annehmen, dass hochfrequente Wellen zu einer schnelleren Zerstreuung neigen als niederfrequente, obwohl ähnlich wie der Druck auch die Abschwächungsrate nicht stark von der Frequenz abhängig sein dürfte.
\end{abstract}

\section{INTRODUGTION}

In both Europe and the North American continent, recreational, residential, and industrial use of alpine areas is increasing. Therefore, the problem of snow avalanches is also expected to increase as more people move into mountainous areas during the winter months. On the American continent, relatively few deaths can yet be attributed to avalanches, but the annual death rate can be expected to increase in the future. Also, the annual cost of damage to forested areas and of avalanche control is significant. In view of these problems, a better means of artificially initiating avalanches could somewhat alleviate the avalanche problem.

Explosives are the most commonly used method of releasing snow slopes to avalanche. This is accomplished by means of hand-thrown charges, recoilless rifles, or howitzers. Generally the discharges take place in the snow-pack and below the snow-pack surface. These discharges produce a highly transient load, which in turn sends a shock wave propagating through the snow-pack. In the immediate vicinity of the explosion, much energy is dissipated through inelastic deformation of the snow. As the pressure pulse propagates away from the discharge, it rapidly attenuates due to geometric spreading, energy dissipation, and boundary interaction.

At a sufficient distance from the discharge, the wave amplitude is reduced to a level such that inelastic deformation of the snow becomes insignificant, but considerable attenuation can

\footnotetext{
* On sabbatical leave from the Department of Civil Engineering and Engineering Mechanics, Montana State University, Bozeman, Montana 59717, U.S.A.
} 
still occur due to geometric spreading, scattering effects of the porous structure of snow, and boundary interaction. The arrival of the pressure wave at the boundaries (snow-pack-air or snow-pack-ground surfaces) causes other types of stress waves to form. In particular, Love waves and Rayleigh waves may form and propagate until they either reach the snow-slope boundaries or attenuate to negligible levels. Even at stress levels that do not cause significant inelastic deformation, attenuation still occurs, as Johnston (unpublished) has shown, since the air phase within the snow causes a scattering effect which results in stress-wave attenuation. Apparently this form of attenuation is frequency dependent, since high-frequency waves seem to attenuate more quickly than low-frequency waves (Lang, 1976).

In the region close to an explosive discharge, the pressure wave is a large-amplitude plastic shock wave. For this type of wave, the primary causes of wave attenuation are geometric spreading and plastic deformation of the matrix material, ice. Brown ( 1980 [a], [b]) has already studied the propagation of plastic waves in snow with densities greater than 0.3 $\mathrm{Mg} \mathrm{m}^{-3}$. Brown's studies have shown that snow rapidly attenuates pressure waves due to the large inelastic volumetric deformations that the material undergoes. He found wave speed to be highly pressure dependent, and attenuation was not found to be strongly frequency dependent, which is contrary to the case of low-intensity waves.

Both steady and non-steady waves were considered by Brown (1980[a], [b]). A steady wave is a shock wave in which the wave amplitude and profile do not change as the wave propagates through the material. This idealization simplifies the mathematics of the problem while still allowing the evaluation of many properties of stress waves. However, one cannot determine stress-wave attenuation or alteration of the profile for this type of wave.

The work reported here is concerned with plastic waves in low-density snow. A volumetric constitutive law for low-density snow (Brown, $1980[\mathrm{c}]$ ) is used with the equations of motion and the continuity equation to evaluate the propagation of steady shock waves in low-density snow. This work supplements Brown's ( $1980[\mathrm{a}],[\mathrm{b}]$ ) work for higher-density snow. Since much avalanche control work involves snow with densities less than $0.3 \mathrm{Mg} \mathrm{m}^{-3}$, the work reported here is considered to be particularly relevant.

\section{VOLUMETRIC CONSTITUTIVE LAW FOR LOW-DENSITY SNOW}

The volumetric constitutive law (Brown, $1980[\mathrm{c}]$ ) was formulated by considering the deformation of the ice grains and grain necks constituting the porous material. The ice making up the matrix material was assumed to be a rate-sensitive viscoplastic material. The equation of motion and equation of continuity were solved to describe the deformation of both the ice grains and the intergranular necks. The result then was used to express the rate of change of density in terms of the hydrostatic pressure $p$ applied to the snow. The resulting constitutive equation relates the pressure $p$ to the density ratio $\alpha$, where

$$
\alpha=\rho_{\mathrm{m}} / \rho,
$$

and $\rho_{\mathrm{m}}$ and $\rho$ are the mass density of the matrix material (ice) and snow, respectively.

Figure I illustrates the geometry of the model used to develop the volumetric constitutive law. In this figure, the matrix material, ice, was divided into three different regions: (I) the necks that connect the grains, (2) region I in the grain that has no contact area with other grains on its lateral surface, and (3) region 2 which has one or more grain bonds bearing on its lateral surface. The neck was chosen to be that portion of the ice that has a surface with radius of curvature directed outward from the solid phase. This radius is denoted by $R^{\prime}$. The grain body is the main part of the grain that has a surface with a radius directed inward toward the center of the grain body. $R$ is taken to be the grain radius. Figure $\mathrm{I}(\mathrm{b})$ shows the idealized geometry that was used to determine the deformation of the ice grain during deformation. The necks were idealized by a cylindrical shape with a constant cross-sectional radius $\Delta$. 


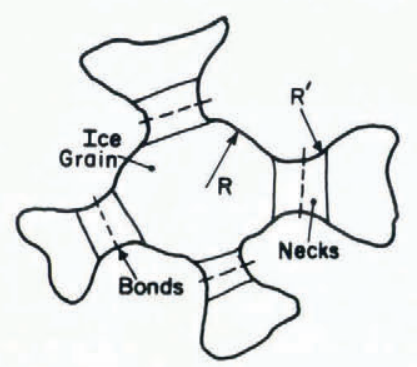

o. TYPICAL GRAIN AND NECK GEOMETRY

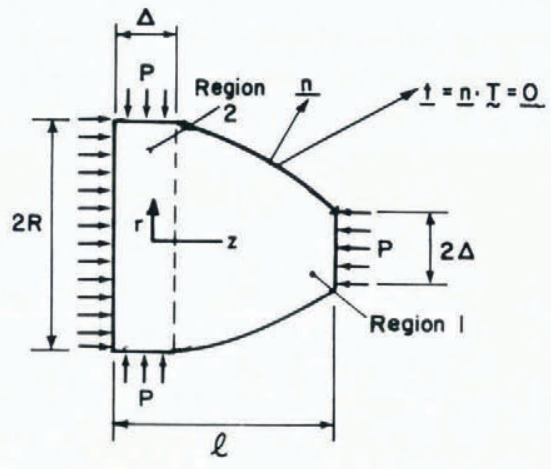

b. IDEALIZED GRAIN GEOMETRY

Fig. I. Geometry of granular structure of snow and idealized model.

The deformations of the three regions were individually determined by use of the equation of continuity and equation of motion. The calculated deformation of the necks and grains were then related to the volumetric deformation of the porous material, snow, to obtain the resulting volumetric constitutive law. This equation (Brown, $1980[\mathrm{c}]$ ), which relates the deformation to the pressure $p$, has the form

$$
\dot{\alpha}=A_{1} \exp \left(\beta_{1} p / F\right)+A_{2} \exp \left(\beta_{2} p / F\right),
$$

where the superposed dot implies differentiation with respect to time. In the above

$$
\begin{aligned}
A_{1} & =(2 \Delta / 3 A)\left[-2 \Delta /\left(R^{2}-\Delta^{2}\right)^{\frac{1}{2}}+B_{1}\right] \exp \left(-S_{0} / C\right), \\
A_{2} & =(R / 3 A)\left[2 R /\left(R^{2}-\Delta^{2}\right)^{\frac{1}{2}}+B_{2}\right] \exp \left(-S_{0} / C\right), \\
\beta_{1} & =(2 \alpha / 3 C)(R / \Delta)^{2}, \\
\beta_{2} & =(\alpha / C)(R / \Delta)^{2}(f-\mathrm{I}), \\
F & =C \rho_{0}\left(\alpha / \alpha_{0}\right)_{2}+C_{3} \rho_{0}, \\
B_{1} & \left.=\left(2 / \mathcal{N} L^{2}\right)\left(4-\frac{2}{3} \mathcal{N}\right) R^{2}+\mathcal{N}\left(2 R^{2}+\Delta^{2}\right) / 3\right), \\
B_{2} & =-\left(2 / \mathcal{N} L^{2}\right)\left[\mathcal{N} \Delta L+2 \mathcal{N} R \Delta / 3-\left(2 R^{2}+\Delta^{2}\right) \Delta \mathcal{N} /(3 R)\right], \\
\mathcal{N} & =4[\mathrm{I}+(\rho-0.30) / 0.50], \\
f & =\frac{1}{2}(\mathrm{I}+\mathrm{I} / \alpha),
\end{aligned}
$$

$R$ and $\Delta$ are, respectively, the grain and neck radii, and $L$ is the neck length. $A, C$, and $S_{0}$ are all material constants for ice. $\mathcal{N}$ is the average number of bonds per grain.

The second expression on the right-hand side of Equation (2) reflects the contribution of deformation of the ice grain, whereas, the first expression on the right-hand side gives the effect of the neck deformation. Brown ( 1980 [c]) found that for a wide range of densities (generally greater than o. $\mathrm{Mg} \mathrm{m}^{-3}$ ) the second term was negligible compared with the first term. Consequently, the simplified equation,

$$
\dot{\alpha}=A_{\mathrm{I}} \exp \left(\beta_{\mathrm{I}} p / F\right),
$$

is used. The rates of change of the neck radius and neck length are given by the expressions

$$
\begin{aligned}
& \dot{\Delta}=\left({ }_{2} \Delta /{ }_{3} A\right) \exp \left[\left(3 \alpha p /{ }_{2} C\right)(R / \Delta)^{2}-S_{0} / C\right], \\
& \dot{L}=B_{1} \dot{\Delta}+B_{2} \dot{R} .
\end{aligned}
$$

In Equation (14) the term $B_{2} \dot{R}$ can be neglected in comparison with the first part, $B_{1} \dot{\Delta}$. The constitutive equation has been shown to represent adequately the response of snow for 
densities ranging from $0.1 \mathrm{Mg} \mathrm{m}^{-3}$ to $0.75 \mathrm{Mg} \mathrm{m}^{-3}$ and for density-ratio rates ranging from $-10^{-5} \mathrm{~s}^{-1}$ to as high as $-100 \mathrm{~s}^{-1}$. Figure 2 shows the comparison of Equation (12) with averaged experimental data (Abele and Gow, 1975, 1976) for compaction of snow. As can be seen, Equation (12) appears to work well.

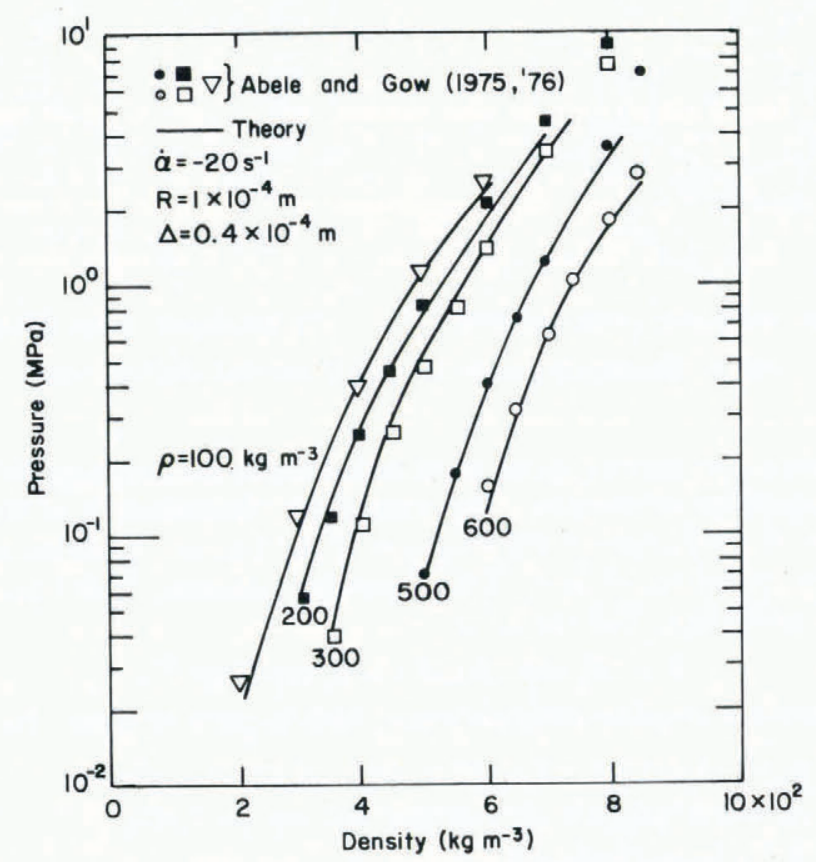

Fig. 2. Comparison of volumetric constitutive law with experimental data.

In the case of large strain-rates which produce significant inertial effects, intergranular dynamical effects must be taken into account. This can be done by rewriting Equation (12) to include an intergranular acceleration term in much the same way as was done earlier (Brown, $1980[\mathrm{a}]$ ) for medium-density snow. This gives

$$
p=\frac{F}{\beta_{\mathrm{I}}} \ln \left(\dot{\alpha} / A_{\mathrm{I}}\right)+\frac{\tau^{2}}{\alpha} Q(\alpha, \dot{\alpha}, \ddot{\alpha}),
$$

where

$$
\begin{aligned}
Q & =-\ddot{\alpha}\left[(\alpha-\mathrm{I})^{-\frac{1}{3}}-\alpha^{-\frac{1}{3}}\right]+\frac{1}{6} \dot{\alpha}^{2}\left[(\alpha-\mathrm{I})^{-4 / 3}-\alpha^{-4 / 3}\right], \\
\tau^{2} & =\rho_{\mathrm{m}} a_{0}^{2} /\left[3\left(\alpha_{0}-\mathrm{I}\right)^{\frac{2}{3}}\right],
\end{aligned}
$$

$a_{0}$ is the initial average void radius in the material.

\section{ANALYsis}

We consider here the propagation of plane plastic waves. The equation of motion is

$$
\nabla_{X} \cdot \mathbf{T}^{0}+\rho_{0} \mathbf{b}_{0}=\rho_{0} \frac{\mathrm{d}^{2} \mathbf{x}}{\mathrm{d} t^{2}},
$$

where $\mathbf{T}^{0}$ is the Piola stress tensor, $\rho_{0}$ is the initial density, $\mathbf{b}_{0}$ is the body force, $X$ is the position of a particle in the undeformed configuration and $\mathbf{x}$ is the particle position in the deformed 
position. If the wave is propagating in the $X$ direction, and if body forces are negligible, Equation (19) reduces to

$$
-\frac{\partial p}{\partial X}=\rho_{0} \frac{\partial v}{\partial t}
$$

where $v$ is the particle velocity in the $X$ direction.

The continuity condition, which places a mass-conservation restriction on the deformation has the Lagrangian form

$$
\frac{\mathrm{d}}{\mathrm{d} t}(\rho \mathcal{f})=\mathrm{o},
$$

where $\mathcal{F}$ is the Jacobian of the deformation and is expressible as the determinant of the deformation gradient. Expanding this equation results in the following form for the continuity equation

$$
\frac{\partial v}{\partial X}=\frac{1}{\alpha_{0}} \frac{\partial \alpha}{\partial t} .
$$

Assume the pressure wave to be steady. Then the governing differential equations may be expressed in terms of the variable $\eta$,

$$
\eta=X-V t,
$$

where $V$ is the stress-wave speed. Then using this, Equations (20) and (22) can be expressed in the following forms:

$$
\begin{aligned}
& \frac{\mathrm{d} p}{\mathrm{~d} \eta}=\rho_{0} V \frac{\mathrm{d} v}{\mathrm{~d} \eta}, \\
& \frac{\mathrm{d} v}{\mathrm{~d} \eta}=-\frac{V}{\alpha_{0}} \frac{\mathrm{d} \alpha}{\mathrm{d} \eta} .
\end{aligned}
$$

These last two equations may be integrated to find the jumps in $p$ and $v$ across the wave forms. Therefore the changes in $p$ and $v$ as the wave passes a fixed point in the snow are

$$
\begin{aligned}
& \left(p-p_{0}\right)=\rho_{0} V\left(v-v_{0}\right), \\
& \left(v-v_{0}\right)=-\frac{V}{\alpha_{0}}\left(\alpha-\alpha_{0}\right) .
\end{aligned}
$$

Eliminating $v-v_{0}$ between Equation (26) and (27) gives

$$
\left(p-p_{0}\right)=-\frac{\rho_{0}}{\alpha_{0}} V^{2}\left(\alpha-\alpha_{0}\right) .
$$

Assume the material is initially unloaded and undeformed, and use the star to denote the steady value of the pressure, density ratio, and particle velocity behind the wave. Then $p-p_{0}, \alpha-\alpha_{0}$, and $v-v_{0}$ become $p^{\star}, \alpha^{\star}-\alpha_{0}$, and $v^{\star}$, respectively. Therefore

$$
\begin{aligned}
p^{\star} & =\rho_{0} V v^{\star}, \\
v^{\star} & =-\frac{V}{\alpha_{0}}\left(\alpha^{\star}-\alpha_{0}\right), \\
p^{\star} & =-\frac{\rho_{0} V^{2}}{\alpha_{0}}\left(\alpha^{\star}-\alpha_{0}\right) .
\end{aligned}
$$

These last three equations are the familiar jump equations for stress waves, although usually they are expressed in terms of the density $\rho$ rather than the density ratio $\alpha$.

Now consider Equation (28). Substitute Equation (15) into it to obtain the equation

$$
-\frac{\rho_{0} V^{2}}{\alpha_{0}}\left(\alpha-\alpha_{0}\right)=\frac{\mathrm{I}}{\beta_{\mathrm{I}} F} \ln \left(\dot{\alpha} / A_{\mathrm{I}}\right)+\frac{\tau^{2}}{\alpha} \frac{\mathrm{d}}{\mathrm{d} \alpha} q(\alpha, \dot{\alpha}, \ddot{\alpha}),
$$


where the last expression in Equation (32) is a reorganization of the intergranular dynamical portion of the constitutive equation. Integrating this equation results in

$$
-\frac{\rho_{0} V^{2}}{3 \alpha_{0}}\left(\alpha-\alpha_{0}\right)\left[\alpha^{2}-\frac{\alpha_{0}}{2}\left(\alpha+\alpha_{0}\right)\right]=\int_{\alpha_{0}}^{\alpha} \frac{\alpha}{\beta_{\mathrm{I}} F} \ln \left(\dot{\alpha} / A_{\mathrm{I}}\right) \mathrm{d} \alpha+\tau^{2}\left[q(\alpha)-q\left(\alpha_{0}\right)\right] .
$$

Since the pressure wave is a steady wave, $q$ is zero both before and behind the wave. Therefore, if $\alpha$ is set equal to $\alpha^{\star}$ in Equation (33), and if Equation (28) is substituted into the above,

$$
p^{\star}=3\left[\alpha^{\star 2}-\frac{\alpha_{0}}{2}\left(\alpha^{\star}-\alpha_{0}\right)\right]^{-\mathrm{I}} \int_{\alpha_{0}}^{\alpha^{\star}} \frac{\alpha \ln \left(\dot{\alpha} / A_{\mathrm{I}}\right)}{\beta_{\mathrm{I}} F} \mathrm{~d} \alpha .
$$

To solve these equations, a parametric solution method can be used. Assume a pressure wave produces a pressure $p^{\star}$ and a final density ratio $\alpha^{\star}$. Equation (3I) can then be used to find the wave speed $V$. Then proceed to use a numerical technique to solve the remaining portion of the problem. If $\Delta \alpha$ is an incremental change in $\alpha$, Equation (28) in incremental form can be used to calculate $p$ at $\alpha+\Delta \alpha$. Then Equation (33) is used to find $\dot{\alpha}$ at $\alpha+\Delta \alpha$. From this $\Delta t$ can be calculated from the constitutive equation. By continuing to step forward in increments of $\Delta \alpha$ until $\alpha^{\star}$ is reached, the $\alpha$ profile and $t^{\star}$ can be found. This then characterizes the wave frequency and rate of loading.

\section{DisGUSSION OF RESULTS}

Figures $3-5$ illustrate the results of this study. Unfortunately only a small amount of experimental data is available for a comparison with these results. To date the most comprehensive experimental study is that of Napadensky (1964). However, Napadensky's experiments were conducted with snow with densities of $0.5 \mathrm{Mg} \mathrm{m}^{-3}$ or higher, so a direct comparison with the calculated results here is not possible for low-density snow.

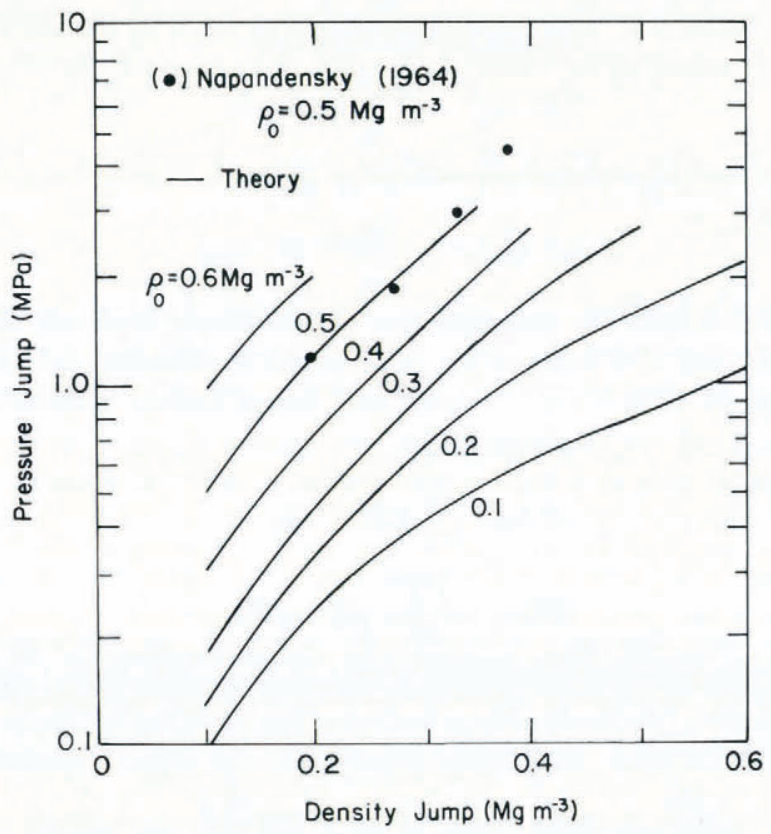

Fig. 3. Variation of pressure jump across a shock wave with density jump. 
Figure 3 illustrates the variation of pressure jump with density jump for several different initial densities, including $0.5 \mathrm{Mg} \mathrm{m}^{-3}$, which is compared with Napadensky's data. As can be seen, the results agree with the data for that initial density. In addition, the calculated curves in Figure 3 compare well with the theoretical calculations reported by Brown (i 980 [a]) for densities larger than $0.3 \mathrm{Mg} \mathrm{m}^{-3}$. In Figures 3 and 4 , the dominant frequency of the wave was $200 \mathrm{kHz}$, which approximately equals the frequencies reported in Brown (1980[a]). This frequency would correspond to what is produced by high-speed explosives.

Figure 4 shows the manner in which the wave speed varies with the wave intensity as determined by the pressure jump. These results also agree with the results of Brown ( 1980 [a]). In particular, for each initial density the wave speed has a local minimum at low values of wave pressure. This is attributable to the work-hardening properties of snow under volumetric deformations. As the snow is compacted, the necks rapidly thicken, which in part enhances the material strength. In addition, the large deformations which occurs in these necks also work-harden the neck material, thereby further increasing the snow strength. This resulting

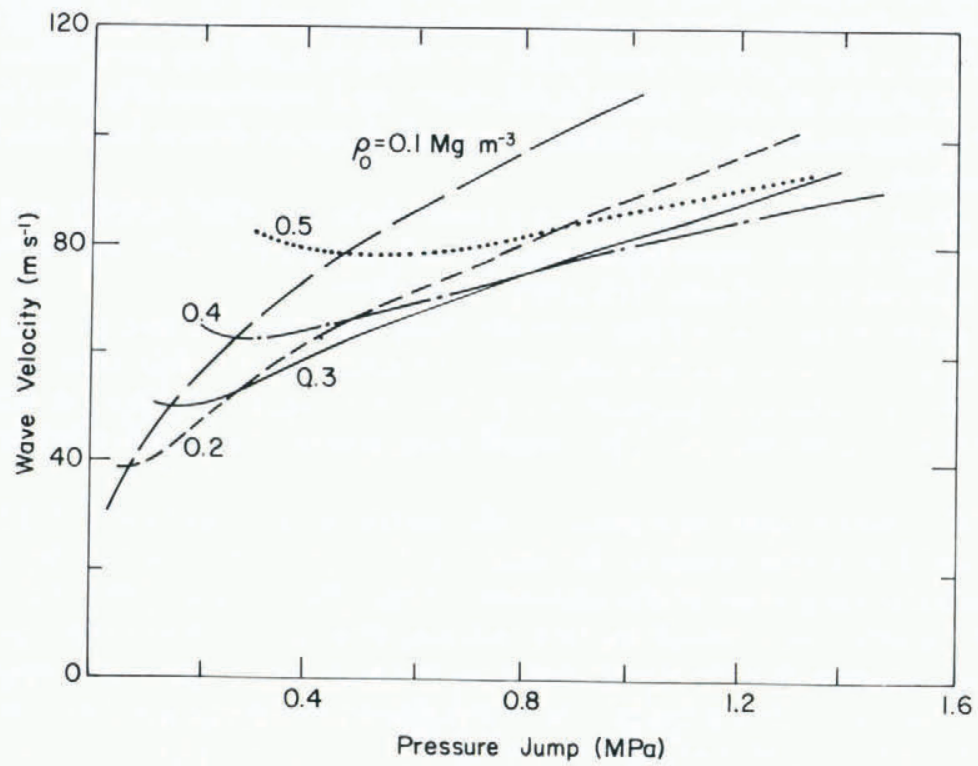

Fig. 4. Effect of pressure jump on shock-wave velocity.

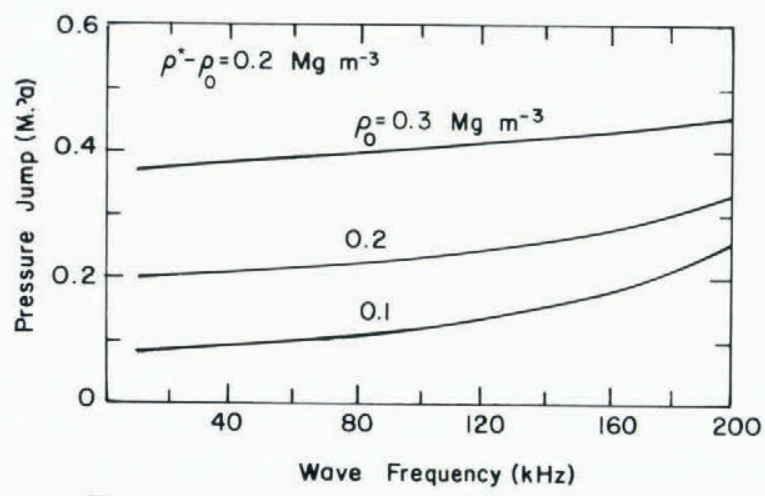

Fig. 5. Effect of shock-wave frequency on pressure jump. 
increase in material strength results in an increased wave speed, since the wave speed is determined by the ratio of $p^{\star} /\left(\alpha^{\star}-\alpha_{0}\right)$, as indicated by Equation (3I).

Figure 5 illustrates the effect of wave frequency on the pressure jump for pressure waves which produce a density jump of $0.2 \mathrm{Mg} \mathrm{m}^{-3}$. Curves are presented for initial densities of $0.1,0.2$, and $0.3 \mathrm{Mg} \mathrm{m}^{-3}$. As can be seen, the pressure jump increases with wave frequency, although the dependence of pressure jump on frequency is not as significant as the dependence on density.

\section{Conclusions}

The stress-wave analysis reported here has been shown to agree well with the only experimental data the author is aware of. Unfortunately the data are available only for snow with an initial density of about $0.5 \mathrm{Mg} \mathrm{m}^{-3}$. Consequently, no definite conclusions can be made about the validity of the theoretical results for snow with initial densities below $0.5 \mathrm{Mg} \mathrm{m}^{-3}$. However, the volumetric equation upon which this study is based has been shown to represent accurately the response of snow under quasi-static load conditions for densities as low as o. I $\mathrm{Mg} \mathrm{m}^{-3}$. Consequently, the low-density stress-wave results shown here should at least be qualitatively correct.

The wave speed was found to be strongly dependent on initial density and the pressure jump across the wave front. Since the pressure is only moderately affected by frequency, the wave speed is also only moderately frequency dependent.

The dependence of wave speed and pressure jump on density is not as straightforward as it is for pressure waves which produce infinitesimal strains. In the case of pressure waves that produce large density changes, pressure jump and wave speed depend on both the initial density $\rho_{0}$ and the final density $\rho^{\star}$. The complicated relationship can readily be observed in Figure 4 .

The type of pressure wave described in this paper is not commonly found in Nature. However, it does play a central role in determining the effectiveness of explosives in initiating avalanches, since a good portion of the explosive energy that is transmitted to the snow-pack is absorbed in the crater zone through inelastic compaction of the snow. This type of deformation also is largely responsible for the attenuation of the pressure wave as it propagates away from the crater formed by the explosive. All of this decreases the energy that is delivered to the snow-pack for the purpose of starting avalanches.

The result that the wave pressure-jump increases with wave frequency would imply that the energy absorbed irreversibly by the snow also increases with frequency, assuming that $\rho_{0}$ and $\rho^{\star}$ are held constant. This in turn would imply that the attenuation rate would increase with frequency, since larger amounts of energy are dissipated in the snow as frequency increases. However, since this is weakly frequency dependent, the effect of frequency on attenuation rate is probably not as important as $\rho^{\star}$ and $\rho_{0}$ for plastic waves.

\section{Acknowledgement}

The work reported here was done under Army Research Office Grant no. DRXRO-RR P-I54I3-GS. The author would like to express his appreciation to the Army Research Office and the U.S. Army Cold Regions Research and Engineering Laboratory for their assistance and support. 


\section{REFERENGES}

Abele, G., and Gow, A. J. 1975. Compressibility characteristics of undisturbed snow. U.S. Cold Regions Research and Engineering Laboratory. Research Report 336.

Abele, G., and Gow, A. J. 1976. Compressibility characteristics of compacted snow. U.S. Cold Regions Research and Engineering Laboratory. Report 76-2 I.

Brown, R. L. I98o[a]. An analysis of non-steady plastic shock waves in snow. Fournal of Glaciology, Vol. 25, No. 92, p. 279-87.

Brown, R. L. 1980[b]. Pressure waves in snow. Journal of Glaciology, Vol. 25, No. 91, p. 99-107.

Brown, R. L. I980[c]. A volumetric constitutive law for snow based on a neck growth model. Fournal of Applied Physics, Vol. $5^{1}$, No. 1, p. $161-65$.

Johnston, J. B. Unpublished. Stress waves in snow. [Ph.D. thesis, University of Washington, Seattle, Washington, 1978.]

Lang, T. E. 1976. Measurements of acoustic properties of hard-pack snow. Fournal of Glaciology, Vol. I 7, No. 76, p. $269-76$.

Napadensky, H. I964. Dynamic response of snow to high rates of loading. U.S. Cold Regions Research and Engineering Laboratory. Research Report i 19. 